\title{
Facile Determination of Sodium Ion and Osmolarity in Artificial Tears by Sequential DNAzymes
}

\author{
Eun Hye Kim ${ }^{1,2}$, Eun-Song Lee ${ }^{1,2}$, Dong Yun Lee ${ }^{3,4, *}$ (D) and Young-Pil Kim ${ }^{1,2,4,5, *}$ \\ 1 Department of Life Science, Hanyang University, Seoul 04763, Korea; eun727712@hanmail.net (E.H.K.); \\ eunsonamoo@naver.com (E.-S.L.) \\ 2 Research Institute for Natural Sciences, Hanyang University, Seoul 04763, Korea \\ 3 Department of Bioengineering, Hanyang University, Seoul 04763, Korea \\ 4 Institute of Nano Science and Technology, Hanyang University, Seoul 04763, Korea \\ 5 Research Institute for Convergence of Basic Sciences, Hanyang University, Seoul 04763, Korea \\ * Correspondences: dongyunlee@hanyang.ac.kr (D.Y.L.); ypilkim@hanyang.ac.kr (Y.-P.K.); \\ Tel.: +82-2-2220-2348 (D.Y.L.); +82-2-2220-2560 (Y.-P.K.)
}

Received: 7 November 2017; Accepted: 5 December 2017; Published: 7 December 2017

\begin{abstract}
Despite high relevance of tear osmolarity and eye abnormality, numerous methods for detecting tear osmolarity rely upon expensive osmometers. We report a reliable method for simply determining sodium ion-based osmolarity in artificial tears using sequential DNAzymes. When sodium ion-specific DNAzyme and peroxidase-like DNAzyme were used as a sensing and detecting probe, respectively, the concentration of $\mathrm{Na}^{+}$in artificial tears could be measured by absorbance or fluorescence intensity, which was highly correlated with osmolarity over the diagnostic range $\left(R^{2}>0.98\right)$. Our approach is useful for studying eye diseases in relation to osmolarity.
\end{abstract}

Keywords: DNAzyme; osmolarity; sodium ion; salinity; tear; dry eye

\section{Introduction}

Tears are an attractive target for disease diagnosis because they exist as a clear fluid and are excreted in response to metabolic and environmental cues. Among eye diseases, dry eye is a commonly encountered symptom in humans and its incidence has increased considerably in recent years. Increased dryness in human tears can lead to eye diseases that damage the ocular surface and cause inflammation because of the instability of the tear film [1]. While individual objective tests prevail in the diagnosis of dry eye disease, tear osmolarity has been considered an alternative means for the rapid diagnosis of dry eye disease [2], as dry eye patients show increased tear osmolarity. In addition, it has been reported that ocular surface inflammation is accompanied by increased levels of osmolarity in the tear film of dry eye patients [3,4]. Osmolarity is a unit of osmotic concentration expressed as the number of osmoles (Osm) of solute per liter (L), and tear osmolarity is determined using an osmometers to measure the total concentration of all solutes including electrolytes in the tear fluid. Values below $290 \mathrm{mOsm} \mathrm{L}^{-1}$ are considered normal, while values above $316 \mathrm{mOsm} \mathrm{L}^{-1}$ indicate severe dry eye (hyperosmolarity) [5]. However, despite the potential application of osmolarity-based diagnosis, the current method for measuring osmolarity relies exclusively on the use of osmometer, which is a device operated by measuring either freezing point or osmotic pressure of a solution. Therefore, the development of a simple measurement of osmolarity is essential for those who have difficulty purchasing expensive equipment. To this end, we have noted that tear osmolarity is predominantly dependent on the concentration of sodium ion, which is the main electrolytes present in normal human tear fluid (120-170 mM), rather than potassium (6-42 mM), calcium (0.3-2 $\mathrm{mM})$, and magnesium ions $(0.3-1.1 \mathrm{mM})[6,7]$. Although tear salinity contributes to nearly $90 \%$ of total tear osmolarity, few studies have examined the correlation between tear osmolarity and tear salinity. 
Over the past decade, nucleic acid-based assays have been developed because of their high stability, easy preparation, and low cost [8-10]. Single-stranded DNA, such as aptamers and DNAzymes, can function in molecular recognition of a broad number of targets, enabling the development of practical assays without complicated instruments. Although many DNAzyme-based strategies are available for analyzing metal ions [11-13], no studies have detected salinity in tear samples using DNAzymes. Recently, a sodium ion-specific RNA-cleaving single-stranded DNAzyme (ssDNAzyme) was reported [14], which shows high selectivity for $\mathrm{Na}^{+}$over a dynamic range $(0.135-50 \mathrm{mM})$ and was used to image intracellular sodium ions in living cells by cleaving a fluorophore-quencher. Based on this study, we hypothesized that an improved design using this DNAzyme would be useful for rapidly determining tear salinity and osmolarity, as an alternative to the use of classical ion-specific electrodes or osmometers.

Here we report visual detection of sodium ion and relevant osmolarity in artificial tears using sequential DNAzymes. This method generates a colorimetric or a fluorescent signal via a sequential reaction of RNA-cleaving and peroxidase-like DNAzymes. In this regime, $\mathrm{Na}^{+}$-specific RNA-cleaving DNAzyme functions as a target recognition element, whereas peroxidase-like DNAzyme functions as a signal generator $[15,16]$. Sodium ion catalyzes the first DNAzyme, which releases a short DNA fragment (part of peroxidase-like DNAzyme). This results in full activation of peroxidase-like DNAzyme, leading to different detection signals by different substrates like classical peroxidase reactions. Because this output signal is proportional to the concentration of sodium ion as a major tear solute, we compared $\mathrm{Na}^{+}$-dependent signals with osmolarity measured in artificial tears.

\section{Materials and Methods}

\subsection{Materials}

Sodium chloride $(\mathrm{NaCl},>99.5 \%)$, and potassium chloride $(\mathrm{KCl},>99.5 \%)$ were purchased from Junsei Chemical (Tokyo, Japan). Hemin chloride $\left(\mathrm{C}_{34} \mathrm{H}_{32} \mathrm{ClFeN}_{4} \mathrm{O}_{4},>97 \%\right)$ was purchased from Sigma-Aldrich (St. Louis, MO, USA). 3,3',5,5'-Tetramethylbenzidine (TMB) and QuantaRed ${ }^{\mathrm{TM}}$ substrate solution were purchased from Thermo Scientific (Waltham, MA, USA). Microplates (96-well clear or black) were purchased from Corning, Inc. (Corning, NY, USA). Oligonucleotides and modified oilgonucleotides were synthesized and purified by high-performance liquid chromatography or polyacrylamide gel electrophoresis (PAGE) by Integrated DNA Technology, Inc. (IDT, Coralville, IA, USA). Artificial tears (ophthalmic solutions, Hyundai Pharm. Co., Ltd., Seoul, Korea) were purchased from a local drug store in Seoul, Korea.

\subsection{Preparation of DNAzyme-Based Assay}

DNA sequences are presented in Table 1, where probe 1 is a sodium-specific DNAzyme, probe 2 including 3 guanines and internal ribonucleotide adenosine $(\mathrm{rA})$ site is a complementary substrate for probe 1 , probe 3 is a major part of peroxidase-like DNAzyme, and probe 4 is a complementary sequence for probe 3 and cleaved probe 2 . The dsDNA complex (sodium ion-sensing part) was initially prepared in a similar manner as previously described [14]. Briefly, the complex was formed by annealing a mixture of probe $1(5.45 \mu \mathrm{L}$ at $10 \mu \mathrm{M})$ and probe $2(4.55 \mu \mathrm{L}$ at $10 \mu \mathrm{M})$ at a 1.2:1 molar ratio in reaction buffer $(50 \mathrm{mM}$ Bis-Tris containing $1 \mathrm{mM}$ EDTA, $\mathrm{pH} 7.0)$ at room temperature (RT, $\left.23-25^{\circ} \mathrm{C}\right)$ for $1 \mathrm{~h}$ prior to use. As a sodium ion-specific DNAzyme control set, we used the reported NaA43E/S fluorogenic pair [14], where 5'-GCG GCG GTA CCA GGT CAA AGG TGG GTG AGG GGA CGC CAA GAG TCC CCG CGG TTA GAT AGA G-3' (NaA43E) was labeled with Iowa Black FQ quencher at its $3^{\prime}$ end and 5'-CTC TAT CTA TrA GGA AGT ACC GCC GC-3' (NaA43S) was 6-carboxyfluorescein fluorophore (FAM) and Iowa Black FQ quencher at its $5^{\prime}$ and $3^{\prime}$ end, respectively. 
Table 1. List of oligonucleotides used in the present study.

\begin{tabular}{|c|c|c|c|}
\hline DNA & Characteristic & Sequence $^{1}$ & Length (bp) \\
\hline Probe 1 & DNAzyme 1 & 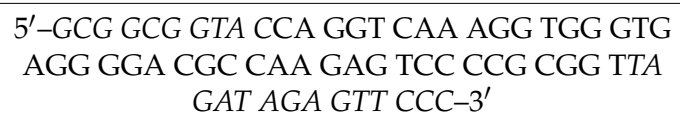 & 66 \\
\hline Probe 2 & Complementary strand 1 & $5^{\prime}-G G G \frac{A A C \text { TCT ATC TAT }}{C G C-3^{\prime}}$ AGG AAG TAC CGC & 30 \\
\hline Probe 3 & DNAzyme 2 & $\begin{array}{l}5^{\prime} \text {-ATT ACA ATT ACT TAC TAA TGG GTG } \\
\text { GGT GGG TGG GAA CTC TAT CTA T-3' }\end{array}$ & 46 \\
\hline Probe 4 & Complementary strand 2 & $\begin{array}{c}5^{\prime} \text {-ATA GAT AGA GTT } \\
\text { TTA GTA AGT AAT TGT AAT-3' }\end{array}$ & 30 \\
\hline
\end{tabular}

${ }^{1}$ The complementary sequence between probe 1 and probe 2 is shown in italics and the complementary sequence between probes $2 / 3$ and probe 4 is underlined. The peroxidase-like DNAzyme sequence is shown in bold.

\subsection{Gel Electrophoresis}

The cleavage of the probe 1 / probe 2 complex was verified by $6 \%$ native PAGE. Initially, the DNA complex (final $1 \mu \mathrm{M}, 60 \mu \mathrm{L}$ ) was incubated for $1 \mathrm{~h}$ at RT with different metal ions (final $135 \mathrm{mM}, 40 \mu \mathrm{L}$ ) or different concentrations of artificial tear solution $(0-100 \%, 40 \mu \mathrm{L})$ in reaction buffer. The resulting product $(9 \mu \mathrm{L})$ and $10 \times$ gel loading buffer $(1 \mu \mathrm{L}$, TaKaRa) was loaded on a polyacrylamide gel. Gel electrophoresis was performed at $25 \mathrm{~mA}$ for $20 \mathrm{~min}$ in $1 \times \mathrm{TB}$ buffer ( $\mathrm{pH}$ 8.0). After the gel was stained in a solution containing GelRed, the gel image was obtained using a UV-transilluminator (BioDoc-It ${ }^{2}$, UVP, Upland, CA, USA) at an excitation wavelength of $302 \mathrm{~nm}$.

\subsection{Detection of Salinity Using Dual DNAzymes}

To determine salinity in buffer or artificial tears, $60 \mu \mathrm{L}$ of the annealed complex (final $1 \mu \mathrm{M}$ ) was incubated with $40 \mu \mathrm{L}$ of sodium ion solution or artificial tear solution in distilled water at RT for $1 \mathrm{~h}$. A stock solution of sodium ion $(135 \mathrm{mM}$ ) or artificial tear (containing $127 \mathrm{mM} \mathrm{NaCl}$ and $17 \mathrm{mM} \mathrm{KCl}$ ) was diluted in the reaction buffer and prepared at final concentrations of $0-100 \%$ at $20 \%$ intervals. The resulting product $(50 \mu \mathrm{L})$ was reacted with probe $3(50 \mu \mathrm{L}$ at $1 \mu \mathrm{M})$ and probe $4(50 \mu \mathrm{L}$ at $1 \mu \mathrm{M})$ by serial incubation of $5 \mathrm{~min}$ at $95^{\circ} \mathrm{C}$ and $25 \mathrm{~min}$ at RT, which was followed by the addition of hemin solution $(8 \mu \mathrm{L}$ at $12.5 \mu \mathrm{M})$ and binding buffer $(42 \mu \mathrm{L}$ at $40 \mathrm{mM}$ Tris containing $200 \mathrm{mM} \mathrm{NaCl}, 50 \mathrm{mM} \mathrm{KCl}$, and $20 \mathrm{mM} \mathrm{MgCl}_{2}$ ) to the mixture at a final volume of $200 \mu \mathrm{L}$. This solution was incubated for $1 \mathrm{~h}$ at RT to generate a G-quadraplex structure. Next, to induce absorbance or a fluorescence signal, $100 \mu \mathrm{L}$ aliquot of the final reactant was transferred into a 96-well microplate (clear plate for absorbance measurement or black plate for fluorescence measurement). Next, $100 \mu \mathrm{L}$ of TMB-containing reaction solution (colorimetric substrate) or $100 \mu \mathrm{L}$ of QuantaRed-containing reaction solution (fluorescence substrate) was added to each microplate well before recoding the signal change. Typically, the absorbance or fluorescence intensity was measured 15 min after the reaction using a multimode plate reader (Varioskan, Thermo Scientific, Inc., Waltham, MA, USA) and a time-dependent signal was acquired using the multimode plate reader every $5 \mathrm{~min}$ for $1 \mathrm{~h}$ at an excitation/emission of $560 \mathrm{~nm} / 580 \mathrm{~nm}$ (for QuantaRed) or absorbance of $650 \mathrm{~nm}$ (for TMB). The color images of absorbance and fluorescence were acquired using a mobile camera and fluorescence imaging system in a black-chambered box (KIF-300, Korea Lab Tech, Korea), respectively.

\subsection{Analysis of Osmolarity in Artificial Tear}

The osmolarity of artificial tear was measured using a micro-osmometer (Fiske Model 210, Advanced Instruments, Norwood, MA, USA) via freezing-point depression. Typically, a $20 \mu \mathrm{L}$ aliquot sample of artificial tear solution (0-100\%) was measured in a disposable tube and the mean value was calculated from triplicate experiments. 


\section{Results and Discussion}

\subsection{Principle of Detection}

As illustrated in Figure 1, sodium ions can be detected by a series of DNAzyme reactions. DNAzyme 1 ( $\mathrm{Na}^{+}$-specific DNAzyme), a sequence modified by attaching CCC to the $3^{\prime}$-end of $\mathrm{NaA} 43$ trans-form reported previously [14], promotes the cleavage of an internal ribonucleotide adenosine (rA) site in the complementary strand upon the addition of $\mathrm{Na}^{+}$. This leads to the release of a short DNA fragment (a part of peroxidase-like DNAzyme including GGG), which can be assembled into whole DNAzyme 2 (peroxidase-like DNAzyme) in the complementary strand 2, where the apo-enzyme is activated in the presence of hemin (an iron-containing porphyrin derivative as a cofactor for DNAzyme), as reported previously [17-19]. It is important to note that the increased peroxidase activity of hemin by G-rich sequences has been found in telomeres, gene promoters and RNA transcripts, accounting for oxidative regulation of gene expression within cells [20]. By this principle, colorimetric or fluorogenic signals can be generated by DNAzyme 2 with different substrates. The sequences of used oligomer probes (1-4) are listed in Table 1. Because DNAzyme 2 can be reassembled from two pieces [21], we asymmetrically split the full sequence of peroxidase-like DNAzyme (5'-GGG TGG GTG GGT GGG TGG G-3', 19 bp) into 5'-GGG-3' (3 bp) and 5'-TGG GTG GGT GGG TGG G-3' (16 bp), which were included in probe 2 and probe 3, respectively, to silence enzyme function under $\mathrm{Na}^{+}$-deficient conditions (bold gray color in Table 1). To induce a strong association between probe 3 and 4, a complementary sequence was appended to the 3' end of probe 3. In this design, two DNAzyme reactions enable increase of $\mathrm{Na}^{+}$-specific signals and generation of different detection modes, which cannot be easily accomplished using a single DNAzyme.

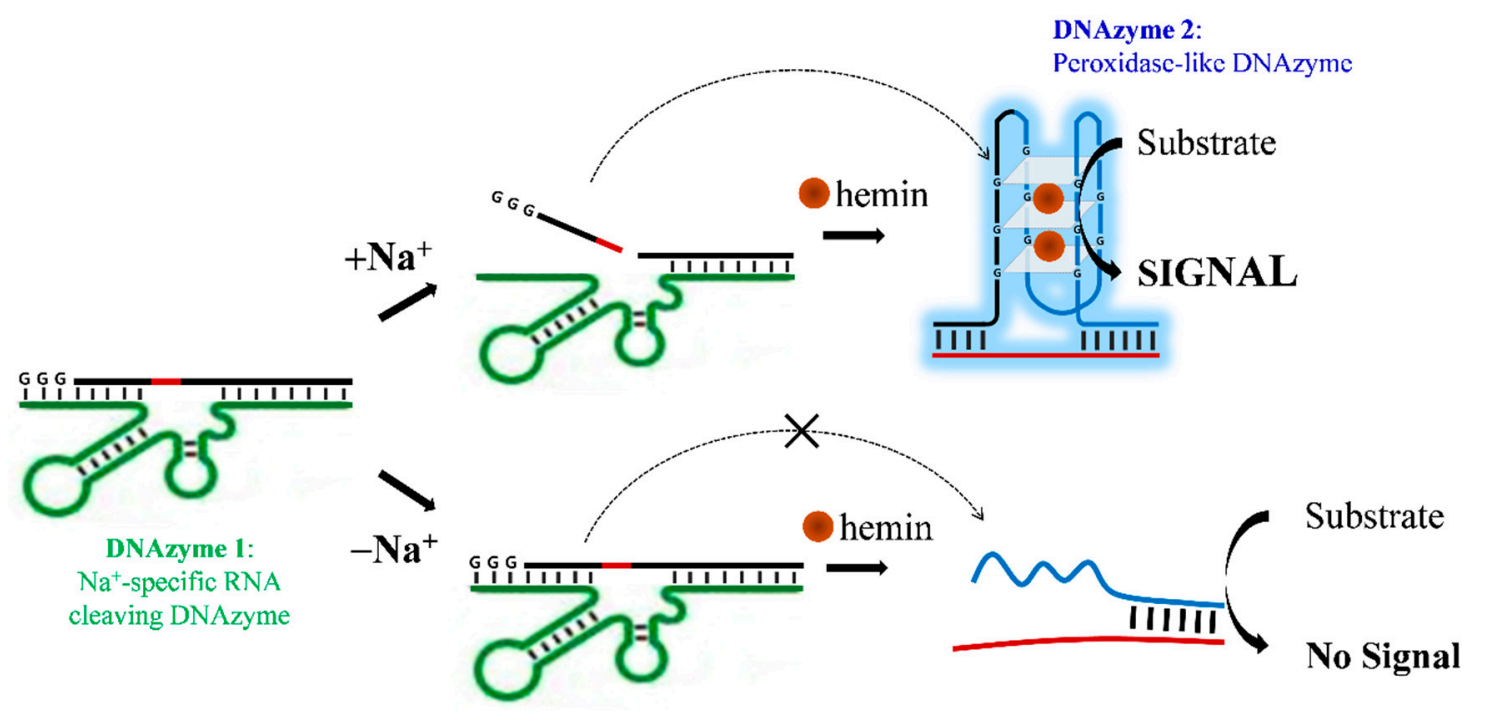

Figure 1. Schematic representation of DNAzyme-based detection of sodium ion $\left(\mathrm{Na}^{+}\right)$. This assay consists of two different DNAzymes: DNAzyme $1\left(\mathrm{Na}^{+}\right.$-specific RNA-cleaving DNAzyme) as a target recognition element and DNAzyme 2 (peroxidase-like DNAzyme) as a signal generator. The short DNA fragment released by $\mathrm{Na}^{+}$-triggered DNAzyme 1 fully activates DNAzyme 2 in the presence of hemin (co-factor) and the measurement mode can be varied depending on the substrates used.

\subsection{Sensing Sodium Ions in Artificial Tear}

We investigated the $\mathrm{Na}^{+}$-dependent cleavage of dsDNA complex by gel electrophoresis (Figure 2). In Figure 2A,B, when probe 1 (66 bp in lane 2) and probe 2 (30 bp in lane 1) were mixed, a strong new band corresponding to a dsDNA conjugate was observed, with a reduced intensity of each ssDNA (96 bp in lane 3). We incubated this assembly (probes 1 and 2) with different types of ions (Figure 2A) and different concentrations of artificial tears (Figure 2B). As a result, the cleaved band 
( 15 bp each from probe 2 ) was observed only in the presence of sodium ion, but not in the other samples (lanes 4-7 in Figure 2A). In addition, artificial tear also showed increased band intensity of the cleaved fragments as the band intensity of dsDNA decreased in a manner proportional to the concentration of artificial tears (lanes 4-8 in Figure 2B). Considering that the artificial tear used in this study contained $127 \mathrm{mM} \mathrm{NaCl}_{1} 12 \mathrm{mM} \mathrm{KCl} 2 \mathrm{mg} \mathrm{mL}^{-1}$ hypromellose (emulsifier), sodium hyaluronate (lubricant), phosphate ions, and sodium hydroxide, sodium ion was a major contributor to this reaction. Therefore, this result strongly indicates that sodium ion in the artificial tear enabled cleavage of the complex of probes $1 / 2$, leading to a rapid release of the short DNA fragment from probe 2 .

(A)

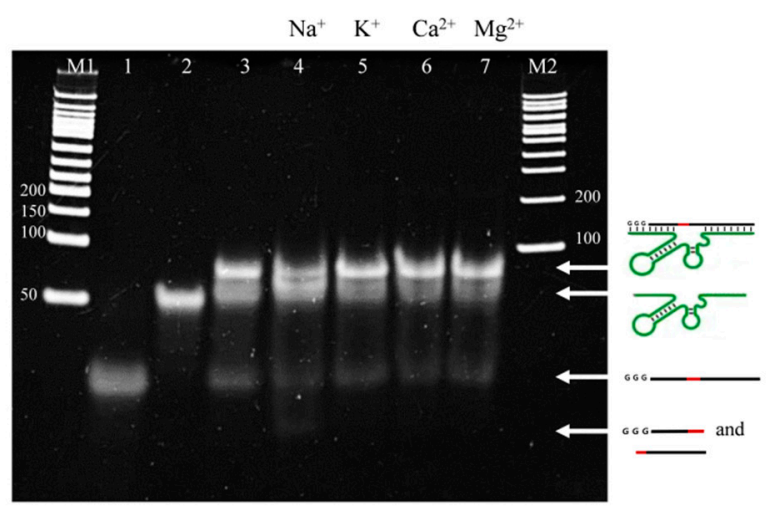

(B)

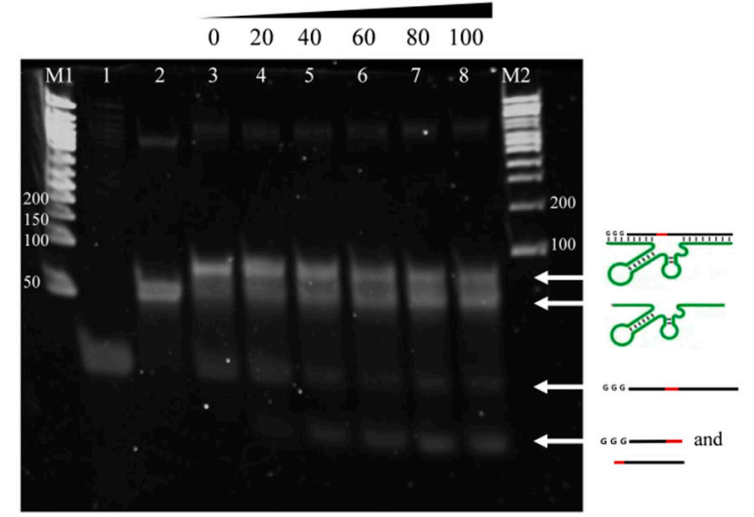

Figure 2. Gel electrophoretic images representing the cleavage of dsDNA (probes 1 and 2) at different ions (A) or at different concentrations of artificial tears (B). In (A) and (B), the first 3 lanes are the same; ssDNA probe 2 (lane 1), ssDNA probe 1 (lane 2), and dsDNA of probe 1/2 (lane 3). M1 and M2 indicate different DNA size markers. Lanes 4-7 in (A) represent the additions of $\mathrm{Na}^{+}$(lane 4), $\mathrm{K}^{+}$(lane 5), $\mathrm{Ca}^{2+}$ (lane 6), and $\mathrm{Mg}^{2+}$ (lane 7), whereas lanes 4-8 in (B) represent the additions of different concentrations of artificial tears (20,40,60, 80, and 100\%). Gel electrophoresis was performed on a $6 \%$ native polyacrylamide gel at $25 \mathrm{~mA}$ for $20 \mathrm{~min}$ in $1 \times \mathrm{TB}$ and images were acquired on a UV transilluminator. The final concentration of monovalent and divalent ions was $135 \mathrm{mM}$.

Next, we examined whether DNAzyme 2 was activated by DNAzyme 1. As shown in Figure 3A, when the mixture of probe $1-4$ was treated with $\mathrm{K}^{+}$or $\mathrm{Na}^{+}$at different concentrations $(0,10,50$, and $135 \mathrm{mM}$ ), the reaction was detected using TMB as a chromogenic substrate (Figure 3B) or QuantaRed as a fluorogenic substrate (Figure 3C) in the presence of $\mathrm{H}_{2} \mathrm{O}_{2}$. As the concentration of sodium ion increased, color intensity, which could be directly observed by eye, increased in yellow (top image in Figure 3B) and fluorescent emission also increased in red (top image in Figure 3C). In contrast, there were no significant signals in $\mathrm{K}^{+}$-treated samples (bottom images in Figure 3B,C). Notably, metal ions can affect the activity of peroxidase-like DNAzyme because the hemin-mediated G-quadruplex is formed in the presence of metal ions (particularly $\mathrm{K}^{+}$ion) [11]. In addition, it was reported that $\mathrm{Na}^{+}$ions can induce a conformational transition in the G-quadruplex, leading to reduced enzyme activity [12,22]. Our method avoids this problem as the tested ions were initially reacted with DNAzyme 1 in salt-free buffer, but not with DNAzyme 2. The detection limit of $\left[\mathrm{Na}^{+}\right]$was estimated to be $14.6 \mathrm{mM}$ in absorbance and $0.4 \mathrm{mM}$ in fluorescence based on $3 \times$ standard deviations of background signal, which is more improved to that of fluorogenic detection using $\mathrm{Na}^{+}$-specific DNAzyme [14]. Considering that the concentration of $\mathrm{Na}^{+}$ions in human tears varies from 120 to $170 \mathrm{mM}$ [6], the detection sensitivity of this assay is within an applicable range. This result demonstrates that full activation of split DNAzyme 2 was induced by sodium ion-triggered DNAzyme 1 reaction and that this method allows for different detection modes. The ability to exploit different measurement modes using same DNA probes can provide versatile strategy in measuring osmolarity. For example, 
colorimetric analysis can be used in places where equipment is not needed, and fluorescence analysis can be used effectively for more accurate and precise analysis.

(A)

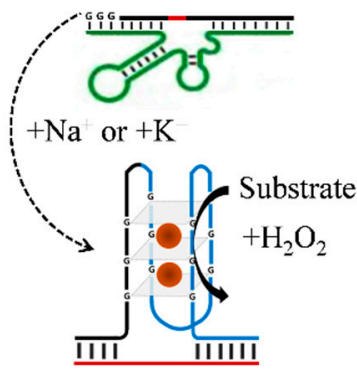

(B)

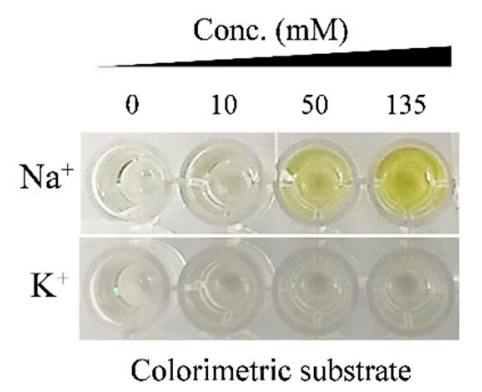

(C)

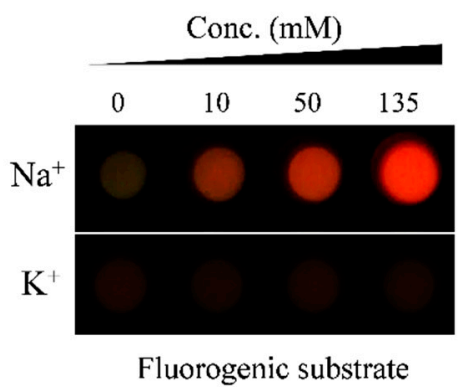

Figure 3. $\mathrm{Na}^{+}$-specific reaction of sequential DNAzymes with different detection mode: (A) schematic of DNAzyme reactions, (B) colorimetric analysis and (C) fluorescent analysis. Each signal by $\mathrm{Na}^{+}$or $\mathrm{K}^{+}$ions was compared as a function of concentration $(0,10,50$, and $135 \mathrm{mM})$.

To gain an insight into the time-dependent reaction of artificial tears by DNAzymes, we tested various concentrations of artificial tears using sequential DNAzymes, wherein colorimetric or fluorescent signals were monitored using different peroxidase-reactive substrates over time (Figure 4). This experiment provides information on the minimum measurement time that current probes can detect $\left[\mathrm{Na}^{+}\right]$in tear sample and information on how fast the DNAzyme reacts with each substrate. When signal outputs were expressed as absorbance (using TMB in Figure 4A) or fluorescence (using QuantaRed in Figure $4 \mathrm{~B}$ ) with variable scales, the change in absorbance (A) or fluorescence $\left(F / F_{0}\right)$ was rapidly saturated with a steep initial slope. Half time at maximal values $\left(t_{1 / 2}\right)$ at different concentrations of artificial tears were determined to be 5-8 min as shown in Figure $4 \mathrm{~A}$ and 2-3 min as shown in Figure $4 \mathrm{~B}$. This minor difference in $t_{1 / 2}$ may be attributed to different substrate reactivities for peroxidase-like DNAzyme, but the overall range of $t_{1 / 2}$ values was sufficiently rapid and similar to that by fluorogenic $\mathrm{Na}^{+}$-specific DNAzyme (data not shown), suggesting that the reaction of DNAzyme 1 was initially determined by the end product from DNAzyme 2. Importantly, the change in maximal equilibrium increased as the concentration of artificial tears increased, indicating that the cascade reaction by DNAzymes allows for rapid detection of sodium ions in artificial tears with versatile detection modes. Based on this result, we determined minimum reaction time (10-15 min) when the DNAzyme1/DNAzyme2 reactant produces colorimetric or fluorescent signal.

(A)

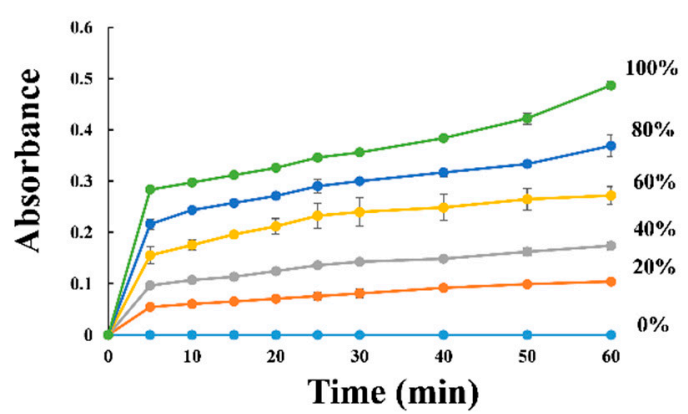

(B)

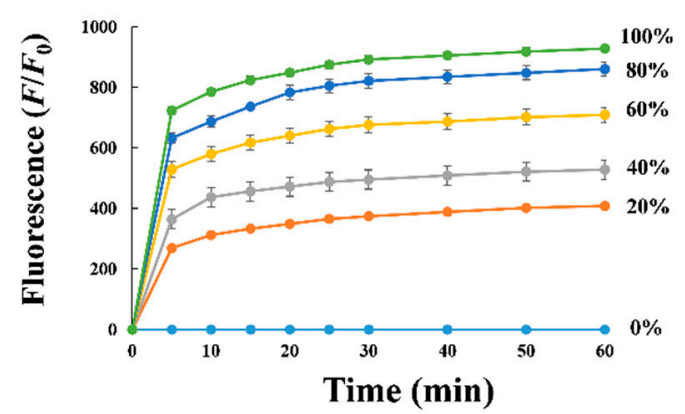

Figure 4. Time-dependent signal generation from sequential DNAzymes at different concentrations of artificial tears. The absorbance was obtained at $650 \mathrm{~nm}$ using colorimetric substrate (A) and the fluorescence signal was at excitation/emission wavelengths of $560 \mathrm{~nm} / 580 \mathrm{~nm}$ using fluorogenic substrate (B), which monitored every $5 \mathrm{~min}$ for $1 \mathrm{~h}$. 


\subsection{Correlation between Sodium Ion Concentration and Osmolarity in Artificial Tear}

Based on the above results, we examined whether sodium ion concentration was well-correlated with osmolarity in artificial tears (Figure 5). When artificial tears were diluted in distilled water and tested at $0-100 \%$ concentration, the osmolarity measured by the osmometer increased in proportion to the concentration, where $100 \%$ artificial tear solution (containing $127 \mathrm{mM}$ sodium ions) showed a value of $292 \mathrm{mOsm} \mathrm{L}^{-1}$ (bar graph in Figure 5A). Similarly, the intensities of fluorescence and absorbance images measured by DNAzymes increased in the same concentration range (microplate images in Figure 5A). When two independent data sets were plotted as a function of tear concentration-based osmolarity, there was a hyperbolic dependence in fluorogenic detection (black line in Figure 5B) or linear dependence in colorimetric detection (green line in Figure 5B), with the high coefficients of determination $\left(R^{2}\right)$ accounting for the strongly positive relationship between osmolarity and both measurements. This result shows that DNAzyme-based detection of sodium ions in artificial tears is useful for estimating tear osmolarity. Theoretically, tear osmolarity did not represent only the concentration of sodium ions ( $1 \mathrm{mM} \mathrm{NaCl}$ solution generates $2 \mathrm{mOsm} \mathrm{L}^{-1}$ ) because many other ions or molecules (e.g., glucose, metabolite, and hormone) in tears contributed to total tear osmolarity. However, the change in tear osmolarity is likely proportional to that in sodium ions detected by DNAzymes because the amount of $\mathrm{NaCl}$ accounts for approximately $90 \%$ of total tear osmolarity. Notably, elevated osmolarity in tears is primarily related to increased levels of sodium chloride [23]. Particularly, considering that tear osmolarity in dry eye can reach more than $13-34 \mathrm{mOsm} \mathrm{L}^{-1}$ than that in normal tear drops [24,25], this change in osmolarity is equivalent to the signal change in the amount of 7-17 mM increase in sodium ions or $10 \%$ increase in artificial tears, supporting that our data can discriminate the dryness in tear drops by salinity or osmolarity.

(A)

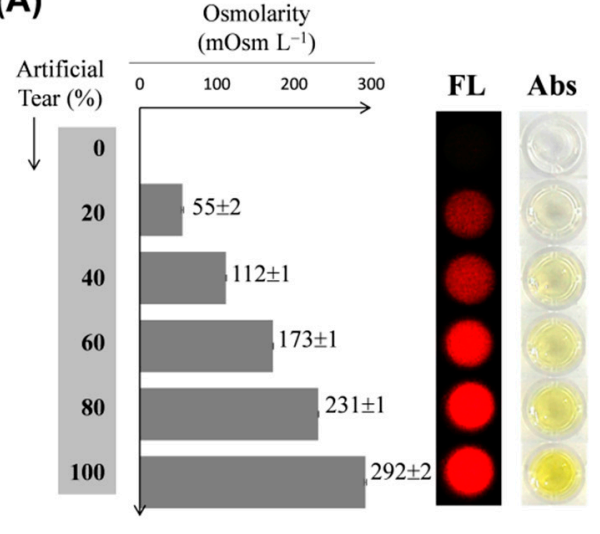

(B)

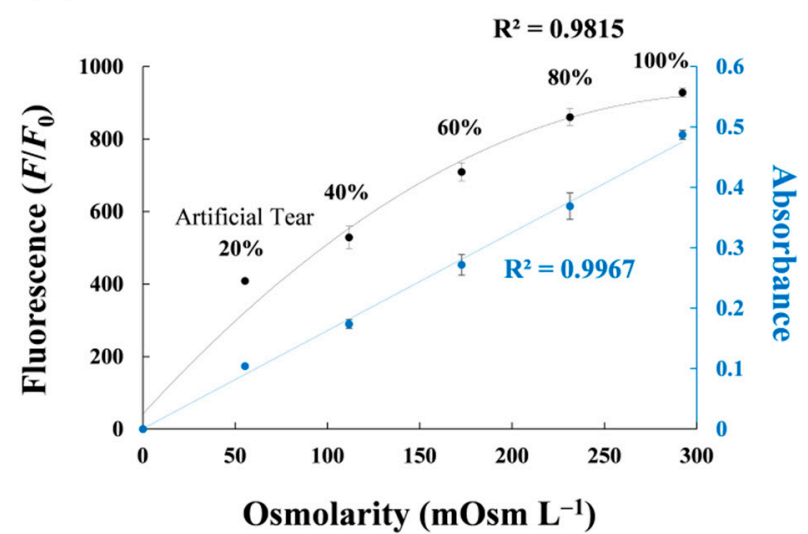

Figure 5. Relationship between osmolarity and sodium ions measured by DNAzymes in artificial tears. (A) Osmolarity (mOsm L ${ }^{-1}$ ) was displayed with gray bars as a function of artificial tear concentration, which was compared with fluorescent (red, left) and colorimetric image (yellow, right) via sequential DNAzyme reactions; (B) The plotted graph represents the relationship between osmolarity and each detection mode as a function of tear concentration. The standard deviation was obtained from three independent experiments.

Despite the availability of chemical [26-29] and electrical impedance-based assays [30] that generally detect sodium ions and osmolarity, DNAzyme-based $\mathrm{Na}^{+}$-assay has many advantages over classical methods. First, the rapid reaction rate $\left(t_{1 / 2}<10 \mathrm{~min}\right)$ and high specificity for sodium ions results in rapid and accurate measurement. In contrast, fluorescence-based chemical probes can induce slow reactivity $\left(t_{1 / 2}>30 \mathrm{~min}\right)$ and cross-reactivity among other metal ions, and other potentiometric ion sensors require sophisticated electrodes. Second, cost-effective and reproducible DNA-based designs allow the user to easily monitor tear osmolarity without the need for expensive osmometers or electric 
devices. Moreover, this method is not limited in fluorescence measurement. Various measurement modes can be used, including colorimetry, fluorescence, and chemiluminescence, which has great potential for versatile applications. Most significantly, unlike blood and urine, tear drops do not contain many biological components that may seriously affect sensing performance. Since tear samples can be directly added to our designed assays without pretreatment, this process is very attractive for in vitro diagnosis or non-invasive clinical tests. However, a small volume of real human tears at sample collection (a few microliters) is the main limitation of this method (typically, this method requires a relatively large volume of $40 \mu \mathrm{L}$ ) although the reaction volume can be reduced by using smaller biochip platforms and the sample can be diluted within a dynamic range. Additionally, in terms of total assay time, our method generally requires more than $1 \mathrm{~h}$ (serial reactions of DNAzyme 1 , assembly, and DNAzyme 2 take at least 30, 30, and $15 \mathrm{~min}$, respectively), which still needs to be reduced considering the relatively rapid measurement time (less than $10 \mathrm{~min}$ ) of osmometer-based analysis [31]. By combining our strategy with microfluidics techniques that consume very small sample volumes with rapid assay time, this method will be practical for diagnosis using real samples. Taken together, current study suggest a new platform for measuring salinity-based osmolarity and is expected to be useful in future tear diagnosis.

\section{Conclusions}

We demonstrated the simple determination of sodium ion-based osmolarity in artificial tears using functional DNAzymes. By consecutively reacting two DNAzymes $\left(\mathrm{Na}^{+}\right.$-specific DNAzyme and peroxidase-like DNAzyme), the concentration of sodium ions in artificial tears was quantitatively determined in colorimetric or fluorescent detection mode. When these detection methods were compared with osmolarity, there was a highly significant correlation between osmolality and $\left[\mathrm{Na}^{+}\right]$in artificial tears. Owing to high relevance of salinity, osmolarity and eye abnormality, our approach is useful for simple diagnostics of ocular diseases.

Acknowledgments: This research was supported by the Bio \& Medical Technology Development Program of the NRF funded by the Korean government, MSIP (NRF-2015M3A9E2030125). This work was also supported by Basic Science Research Program (No. 2012R1A6A1029029) through the NRF funded by the Ministry of Education.

Author Contributions: E.H.K. and E.S.L. performed the experiments and analyzed the data. D.Y.L. and Y.-P.K. were responsible for writing the manuscript and discussion of this work.

Conflicts of Interest: The authors declare no conflict of interest.

\section{References}

1. Gipson, I.K.; Argueso, P.; Beuerman, R.; Bonini, S.; Butovich, I.; Dana, R.; Dartt, D.; Gamache, D.; Ham, B.; Jumblatt, M.; et al. Research in dry eye: Report of the research subcommittee of the international dry eye workshop (2007). Ocul. Surf. 2007, 5, 179-193.

2. Lemp, M.A.; Baudouin, C.; Baum, J.; Dogru, M.; Foulks, G.N.; Kinoshita, S.; Laibson, P.; McCulley, J.; Murube, J.; Pflugfelder, S.C.; et al. The definition and classification of dry eye disease: Report of the definition and classification subcommittee of the international dry eye workshop (2007). Ocul. Surf. 2007, 5, 75-92.

3. Suzuki, M.; Massingale, M.L.; Ye, F.; Godbold, J.; Elfassy, T.; Vallabhajosyula, M.; Asbell, P.A. Tear osmolarity as a biomarker for dry eye disease severity. Investig. Ophthalmol. Vis. Sci. 2010, 51, 4557-4561. [CrossRef] [PubMed]

4. Sullivan, B.D.; Whitmer, D.; Nichols, K.K.; Tomlinson, A.; Foulks, G.N.; Geerling, G.; Pepose, J.S.; Kosheleff, V.; Porreco, A.; Lemp, M.A. An objective approach to dry eye disease severity. Investig. Ophthalmol. Vis. Sci. 2010, 51, 6125-6130. [CrossRef] [PubMed]

5. Tomlinson, A.; Khanal, S.; Ramaesh, K.; Diaper, C.; McFadyen, A. Tear film osmolarity: Determination of a referent for dry eye diagnosis. Investig. Ophthalmol. Vis. Sci. 2006, 47, 4309-4315. [CrossRef] [PubMed]

6. Gilbard, J.P.; Rossi, S.R. Changes in tear ion concentrations in dry eye disorders. Investig. Ophthalmol. Vis. Sci. 1994, 350, 529-533. 
7. Stahl, U.; Willcox, M.; Stapleton, F. Osmolality and tear film dynamics. Clin. Exp. Optom. 2012, 95, 3-11. [CrossRef] [PubMed]

8. Sharma, T.K.; Bruno, J.G.; Dhiman, A. ABCs of DNA aptamer and related assay development. Biotechnol. Adv. 2017, 35, 275-301. [CrossRef] [PubMed]

9. Gedi, V.; Kim, Y.P. Detection and characterization of cancer cells and pathogenic bacteria using aptamer-based nano-conjugates. Sensors 2014, 14, 18302-18327. [CrossRef] [PubMed]

10. Gedi, V.; Song, C.K.; Kim, G.B.; Lee, J.O.; Oh, E.; Shin, B.S.; Jung, M.; Shim, J.; Lee, H.; Kim, Y.P. Sensitive on-chip detection of cancer antigen 125 using a DNA aptamer/carbon nanotube network platform. Sens. Actuators B Chem. 2018, 256, 89-97. [CrossRef]

11. Fan, X.; Li, H.; Zhao, J.; Lin, F.; Zhang, L.; Zhang, Y.; Yao, S. A novel label-free fluorescent sensor for the detection of potassium ion based on dnazyme. Talanta 2012, 89, 57-62. [CrossRef] [PubMed]

12. Sun, H.; Chen, H.; Zhang, X.; Liu, Y.; Guan, A.; Li, Q.; Yang, Q.; Shi, Y.; Xu, S.; Tang, Y. Colorimetric detection of sodium ion in serum based on the G-quadruplex conformation related dnazyme activity. Anal. Chim. Acta 2016, 912, 133-138. [CrossRef] [PubMed]

13. Qin, H.; Ren, J.; Wang, J.; Luedtke, N.W.; Wang, E. G-quadruplex-modulated fluorescence detection of potassium in the presence of a 3500-fold excess of sodium ions. Anal. Chem. 2010, 82, 8356-8360. [CrossRef] [PubMed]

14. Torabi, S.F.; Wu, P.W.; McGhee, C.E.; Chen, L.; Hwang, K.; Zheng, N.; Cheng, J.J.; Lu, Y. In vitro selection of a sodium-specific dnazyme and its application in intracellular sensing. Proc. Natl. Acad. Sci. USA 2015, 112, 5903-5908. [CrossRef] [PubMed]

15. Elbaz, J.; Moshe, M.; Shlyahovsky, B.; Willner, I. Cooperative multicomponent self-assembly of nucleic acid structures for the activation of dnazyme cascades: A paradigm for DNA sensors and aptasensors. Chem. Eur. J. 2009, 15, 3411-3418. [CrossRef] [PubMed]

16. Kosman, J.; Juskowiak, B. Peroxidase-mimicking dnazymes for biosensing applications: A review. Anal. Chim. Acta 2011, 707, 7-17. [CrossRef] [PubMed]

17. Travascio, P.; Li, Y.F.; Sen, D. DNA-enhanced peroxidase activity of a DNA aptamer-hemin complex. Chem. Biol. 1998, 5, 505-517. [CrossRef]

18. Travascio, P.; Bennet, A.J.; Wang, D.Y.; Sen, D. A ribozyme and a catalytic DNA with peroxidase activity: Active sites versus cofactor-binding sites. Chem. Biol. 1999, 6, 779-787. [CrossRef]

19. Li, W.; Li, Y.; Liu, Z.L.; Lin, B.; Yi, H.B.; Xu, F.; Nie, Z.; Yao, S.Z. Insight into G-quadruplex-hemin dnazyme/rnazyme: Adjacent adenine as the intramolecular species for remarkable enhancement of enzymatic activity. Nucleic Acids Res. 2016, 44, 7373-7384. [CrossRef] [PubMed]

20. Cheng, X.H.; Liu, X.J.; Bing, T.; Cao, Z.H.; Shangguan, D.H. General peroxidase activity of G-quadruplex-hemin complexes and its application in ligand screening. Biochemistry 2009, 48, 7817-7823. [CrossRef] [PubMed]

21. Deng, M.G.; Zhang, D.; Zhou, Y.Y.; Zhou, X. Highly effective colorimetric and visual detection of nucleic acids using an asymmetrically split peroxidase dnazyme. J. Am. Chem. Soc. 2008, 130, 13095-13102. [CrossRef] [PubMed]

22. Sen, D.; Gilbert, W. A sodium-potassium switch in the formation of four-stranded G4-DNA. Nature 1990, 344, 410-414. [CrossRef] [PubMed]

23. Pflugfelder, S.C. Tear dysfunction and the cornea: LXVIII edward jackson memorial lecture. Am. J. Ophthalmol. 2011, 152, 900-909. [CrossRef] [PubMed]

24. Lemp, M.A.; Bron, A.J.; Baudouin, C.; Del Castillo, J.M.B.; Geffen, D.; Tauber, J.; Foulks, G.N.; Pepose, J.S.; Sullivan, B.D. Tear osmolarity in the diagnosis and management of dry eye disease. Am. J. Ophthalmol. 2011, 151, 792-798. [CrossRef] [PubMed]

25. Potvin, R.; Makari, S.; Rapuano, C.J. Tear film osmolarity and dry eye disease: A review of the literature. Clin. Ophthalmol. 2015, 9, 2039-2047. [CrossRef] [PubMed]

26. Minta, A.; Tsien, R.Y. Fluorescent indicators for cytosolic sodium. J. Biol. Chem. 1989, 264, $19449-19457$. [PubMed]

27. Jayaraman, S.; Song, Y.; Vetrivel, L.; Shankar, L.; Verkman, A.S. Noninvasive in vivo fluorescence measurement of airway-surface liquid depth, salt concentration, and pH. J. Clin. Investig. 2001, 107, 317-324. [CrossRef] [PubMed] 
28. Martin, V.V.; Rothe, A.; Gee, K.R. Fluorescent metal ion indicators based on benzoannelated crown systems: A green fluorescent indicator for intracellular sodium ions. Bioorg. Med. Chem. Lett. 2005, 15, 1851-1855. [CrossRef] [PubMed]

29. Meier, S.D.; Kovalchuk, Y.; Rose, C.R. Properties of the new fluorescent Na+ indicator corona green: Comparison with sbfi and confocal Na+ imaging. J. Neurosci. Methods 2006, 155, 251-259. [CrossRef] [PubMed]

30. Tomlinson, A.; McCann, L.C.; Pearce, E.I. Comparison of human tear film osmolarity measured by electrical impedance and freezing point depression techniques. Cornea 2010, 29, 1036-1041. [CrossRef] [PubMed]

31. Jacobi, C.; Jacobi, A.; Kruse, F.E.; Cursiefen, C. Tear film osmolarity measurements in dry eye disease using electrical impedance technology. Cornea 2011, 30, 1289-1292. [CrossRef] [PubMed]

(C) 2017 by the authors. Licensee MDPI, Basel, Switzerland. This article is an open access article distributed under the terms and conditions of the Creative Commons Attribution (CC BY) license (http:/ / creativecommons.org/licenses/by/4.0/). 